\title{
Alegoria, história e ficção em $O$ outro pé da sereia: uma tessitura pós-colonial
}

\author{
Maria de Fátima Castro de Oliveira Molina ${ }^{1}$
}

\begin{abstract}
RESUMO: A relação do escritor Mia Couto com a história da colonização da África se particulariza na obra $O$ outro pé da Sereia (2006) por meio da recriação de cenários e da reconstrução das vozes que compõem a narrativa. Pelo viés desse diálogo, o romance se destaca devido à carga simbólica que traz na (re)construção ficcional de momentos históricos da colonização portuguesa em Moçambique. Partindo dessa premissa, propomos evidenciar a presença da alegoria no entrelaçamento entre História e ficção como elemento constitutivo do universo ficcional do referido romance.
\end{abstract}

PALAVRAS CHAVE: Alegoria; Ficção; História; Literatura Pós-colonial; Mia Couto.

\begin{abstract}
Mia Couto's relationship with African history of colonization is revealed in his novel $O$ Outro pé da sereia, The Mermaid's Other Foot, (2006). In this work the writer recreates scenes and reconstructs the voices that make up the narrative. Through this dialogue, the novel stands out as very relevant for our studies due to the symbolic weight that it brings in the fictional (re)construction of historical moments during the Portuguese colonialism in Mozambique. From this premise, we propose to explore the presence of allegory in entanglement between history and fiction as a constitutive element in the fictional universe of the novel.
\end{abstract}

KEYWORDS: Allegory; Fiction; History; Literature postcolonial; Mia Couto.

A ficção coutiana numa perspectiva pós-colonial

Mia Couto, escritor moçambicano nascido na Beira, se destaca entre os autores da literatura africana de língua portuguesa pela diversificada produção que levou a literatura de Moçambique a ultrapassar os limites de sua nação, conforme revela um estudo realizado por Ana Cláudia Silva sobre a fortuna crítica do autor. Segundo Silva, a produção de Mia Couto se sobressai pelo entrelaçamento de culturas, pela busca de identidade, pela reflexão sobre o passado colonial e por "ecos amargurados de um país desfeito pela colonização” (2010, p. 72). Dessa forma, a História de Moçambique, aparece reiteradamente como pano de fundo para compor a narrativa dos seus romances, como em Terra Sonâmbula (1992), A varanda do fragipani (1993), O último vôo do flamingo (2000), Um rio chamado tempo, uma casa chamada terra (2002) e o Outro pé da sereia (2006), que em 2007 ganhou o $5^{\circ}$ Prêmio Passo Fundo Zaffari \& Bourbon de

\footnotetext{
1 Doutoranda do Programa Pós-Graduação em Letras: Área Literaturas em Língua Portuguesa, pela Universidade Estadual Paulista Júlio Mesquita Filho, Campus de São José do Rio Preto. Pesquisa: O entrelaçamento entre história e ficção em $\mathrm{O}$ outro pé da sereia, de Mia Couto. Professora do Departamento de Línguas Vernáculas da Universidade Federal de Rondônia fatima-molina@uol.com.br
} 
Literatura, pelo melhor romance publicado em língua portuguesa, obra sobre a qual deteremos nossa análise.

Diante da relação que se instaura entre as obras de Mia Couto e os eventos que marcaram a História de seu país, torna-se compreensível a opção do autor por abordagens que fazem referência ao processo de descolonização, a situação pós-colonial e, posteriormente, o processo de reconstrução de Moçambique. Descrevendo sobre seu envolvimento com esses fatos históricos, o autor explica:

Eu escrevo Terra sonâmbula quando a guerra estava a acontecer; eu escrevo A varanda do frangipani com o período de transição ainda a acontecer; eu escrevo $\mathrm{O}$ último vôo do flamingo já olhando a guerra e o processo de pacificação. Eu acho que o fazer da história está tão presente, ele próprio é tão ficcional, nós estamos vivendo em países que se estão escrevendo eles próprios, estão se inventando, estão nascendo e nós estamos nascendo com eles e não é possível separar uma coisa da outra. E eu sou de tal maneira parte desse processo, desse parto, desse nascimento, que não me vejo existente fora dele, só ali tenho dimensão ${ }^{2}$.

Torna-se evidente, portanto, que em sua proposta de revisitação da História pelo viés da ficção dá visibilidade à tematização não só da guerra, mas também da tradição e do hibridismo cultural, temas que estão diretamente ligados ao processo de reconstrução de Moçambique. Em seu projeto literário, o autor propõe um redimensionamento nas posições ocupadas pelas personagens que constam nos registros oficiais e são inseridas na ficção. Tal estratégia pode ser interpretada como uma forma de dar visibilidade às tensões geradas pelo contato entre colonizador e colonizado em diferentes tempos e espaços.

A adoção dessas estratégias de escrita nos conduz para o entendimento de que a ficcionalização da História pode ser considerada uma das marcas da literatura contemporânea e uma característica singular da literatura produzida pelos países africanos de língua portuguesa que trazem em sua trajetória as marcas da experiência da colonização. Trata-se de uma literatura produzida por países recentemente descolonizados, que ao longo da História viveram subjugados pelo sistema colonial e enfrentaram anos de luta pela libertação. Assim, as manifestações literárias produzidas nos espaços africanos colonizados por Portugal têm o traço comum de potencializar seu poder de intervenção. Conforme destaca Rita Chaves, trata-se de uma produção que

\footnotetext{
${ }^{2}$ Entrevista a Rita Chaves e Tânia Macedo. In: Biblioteca Sonora. RádioUSP, 14 de agosto de 2006.

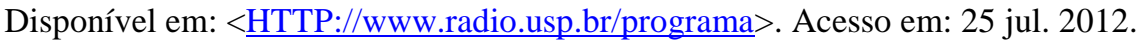


"nasce sob o signo da reivindicação, trazendo para si a função de participar no esforço de construir um espaço de discussão sobre a condição colonial" (CHAVES, 2009, p.8). Assim, embora se sobressaia, nessas obras, o valor estético e a preocupação com a poeticidade, a motivação social também se faz presente, deixando suas marcas de contestações raciais, políticas e culturais. São elementos que por meio da alegoria estão presentes na construção das personagens, em suas atuações nos diferentes tempos e espaços.

Nesse sentido, são produções que, seguindo a análise de Fonseca (2008), partilham do propósito de desarticular posturas de harmonização das diferenças, que buscam se afirmar como vozes e histórias dissonantes que emergem do silêncio a elas imposto ao longo da História. É nesse nível de reflexão que a questão do silêncio é considerada por Santos:

O silêncio é o resultado do silenciamento: a cultura ocidental e a modernidade têm uma ampla experiência histórica de contato com outras culturas, mas foi um contato colonial, um contato de desprezo, e por isso silenciaram muitas dessas culturas, algumas das quais destruíram (2007, p. 55).

Diante de tais fatores, tornam-se compreensíveis as estratégias de criação adotadas por Mia Couto na composição do seu universo ficcional. A configuração de "enquadramentos e ajustamentos culturais das minorias do país, [...] os que vivem 'muito oralmente', esses que representam outro tempo, os sem tempo e fora dele" (LEITE,2009, p. 8), faz o que antes era negligenciado assumir uma posição de destaque com o papel de repensar a cultura, valores e crenças outrora silenciados.

Assim, inerente à inclinação de construir a ficção nas lacunas deixadas pela História, está o trato diferenciado que o autor dá às palavras, detentoras de um poder criador capaz de fundar uma nova realidade cultural tão presente em suas narrativas. No seu fazer literário, a palavra é sempre intensificada de significados, gerando possibilidades para novas interpretações, fato que nos remete às ideias de Alfredo Bosi, ao afirmar que "o poeta é o primeiro a dar, pela própria composição do seu texto, um significado histórico às suas representações e expressões” (BOSI, 2008, p. 142).

O processo de escrita de Mia Couto é marcado pela confluência da oralidade na escrita, bem como por provérbios populares e construções linguísticas utilizadas pelos diferentes grupos étnicos tribos que constituem seu país. A importância dessa recriação verbal é enfatizada neste argumento de Inocência Mata: 
Se a língua é um veículo privilegiado de dominação, é também um veículo de libertação. Em Mia Couto a artesania do verbo é aliada de uma reflexão histórica, político-social e ideológica. Essa artesania é exemplo da criatividade e inventividade liguísticas de literaturas que querem afirmar sua diferença com relação ao colonizador (MATA, 1998, p. 2620).

É em consonância com tais princípios que a obra de Mia Couto se associa a uma vertente literária que se insere no papel da atual literatura pós-colonial. Essa relação também se justifica pelo fato de que as concepções que emergem dessa corrente teórica trazem à cena diferentes enfoques e estratégias no exame da História, literatura e outras formas de experiência cultural. Experiências de alteridade, diferença, identidade cultural, migração, diáspora, escravidão, opressão, resistência, hibridização e representação são algumas das questões debatidas pelos estudos pós-coloniais. Nesse sentido, Fonseca e Cury afirmam que "essas idéias, tão presentes nos romances, configuram a escrita de Mia Couto no contexto das tendências contemporâneas da assim chamada crítica pós-colonial” (2008, p. 107). Sobre o pós-colonialismo, Santos declara:

O pós-colonialismo deve ser entendido em duas acepções: a primeira é a de um período histórico, o que sucede à independência das colônias. A segunda é de um conjunto de práticas (predominantemente performativas) e de discursos que desconstroem a narrativa colonial, escrita pelo colonizador, e procuram substituí-la por narrativas escritas do ponto de vista do colonizado (2010, p. 233).

Feitas essas considerações, compreendemos o papel de destaque que a literatura produzida por Mia Couto assume ao intervir artisticamente na História, diluindo posições hegemônicas e fixas, abrindo espaços de negociações e trocas culturais, valorizando vozes outrora negligenciadas pelo colonialismo.

É Dessa forma, entrelaçando História e ficção, que Mia Couto propõe no romance $\mathrm{O}$ outro pé da sereia uma recontagem da História da colonização de Moçambique por meio da recriação de cenário e da representação das personagens que constituem a narrativa, apresentando por meio dessa revisitação uma nova perspectiva para o fato histórico.

\section{A alegoria em $O$ outro pé da sereia}

O processo artesanal com que Mia Couto constrói seus romances nos remete às concepções de Benjamin em torno da narrativa, considerada pelo autor como uma arte artesanal, um trabalho manual (BENJAMIN, 1994). É com essa configuração que 
visualizamos a escrita poética coutiana, entrelaçando História e ficção, o autor utiliza estratégias que criam imagens e exigem do leitor, um olhar não linear para as temporalidades diversas que se ficcionalizam em sua obra, mas possibilitam uma leitura a contrapelo da História da colonização de Moçambique.

Sobre essas estratégias de escrita, Cury e Fonseca destacam que a "Alegoria seria, então, na proposta literária de Mia Couto, esse recurso privilegiado de escuta, de fazer ouvir as vozes silenciadas pela dominação, subvertendo tempos e espaços” (2008, p. 58). Tal premissa põe em evidência o papel da alegoria como uma estratégia de construção textual ideal para o entrelaçamento das temáticas privilegiadas por Mia Couto na tessitura do romance em referência neste estudo.

Em busca de um aparato teórico para o conceito de alegoria, ancoramo-nos na concepção de João Adolfo Hansen, presente em sua obra Alegoria: construção e interpretação da metáfora (2006). Nessa perspectiva a alegoria é descrita como um processo de criação, um procedimento construtivo, cujas raízes estão no plano linguístico. De forma mais sistemática, conforme define o teórico, a palavra alegoria tem origem grega "(allós=outro; agourein=falar) diz $b$ para significar $a$. A Retórica antiga assim a constitui, teorizando-a como modalidade da elocução, isto é, como ornatus ou ornamento do discurso" (2006, p. 7). Indo mais além, Hansen cita Heinrich Lausberg que, partindo das definições de Aristóteles, Cícero e Quintiliano, redefine a alegoria como "metáfora continuada [...] substituição do pensamento em causa por outro pensamento, que está ligado, numa relação de semelhança, a esse mesmo pensamento" (LAUSBERG apud HANSEN, 2006, p. 7).

Na concepção Walter Benjamin, a alegoria é desenvolvida em dois momentos: primeiro na Origem do Drama Barroco Alemão, contraponto a alegoria ao conceito clássico de símbolo e, posteriormente, nos estudos sobre Baudelaire, afirmando que "a alegoria é a máquina-ferramenta da Modernidade" (BENJAMIN, apud JUNKES, 2008, p. 125). Antes de adentrarmos no conceito benjaminiano de alegoria, é interessante fazermos referência à oposição feita pelo teórico entre alegoria e símbolo, conforme demonstra Lauro Junkes (2008) em O processo de alegorização em Walter Benjamin.

A oposição entre alegoria e símbolo feita por Benjamin, centra-se, de um lado, na aceitação de uma subjetividade criativa e por outro, na renúncia desta. Conforme explica Junkes (2008), tendo como base as ideias de Benjamin, “O símbolo mantém maior afinidade com o nome e tende a negar a participação de qualquer sujeito constituidor do sentido, extinguindo-se a subjetividade do criador" (2008, p. 127). Assim, embora haja a participação de um sujeito em sua criação, o símbolo sempre vai 
expressar seu sentido na forma original, "como resultado de uma conexão objetivamente dada e necessária, excluindo e renunciando a participação de qualquer subjetividade" (2008, p. 127). Em contrapartida, na alegoria há a necessidade da participação do homem na atribuição de sentido, uma vez que a alegoria busca seu sentido no mundo histórico. Logo, o sentido alegórico resulta "da relação subjetiva entre signo e coisa, intensificando o princípio da subjetividade subjacente a todo sentido no mundo histórico" (2008, p. 128). O sentido assim, o não está preso ao elemento simbólico presente na essência da palavra e o homem, nesse processo de atribuir sentido às coisas, não se encontra na situação paradisíaca, atribuindo sentido às coisas na linguagem de Adão.

Dessa forma, a alegoria para Benjamin é um processo de constituição de sentido, sendo fundada num princípio de subjetividade em que "Cada pessoa, cada coisa, cada relação pode significar qualquer outra” (BENJAMIN apud JUNKES, 2008, p. 128-129). A partir dessa premissa, torna-se compreensível a relação da alegoria com o signo linguístico pelo fato de que "no mundo histórico as coisas deixaram de ter sentido em si próprias; o "nome" não mais [...] — as coisas, as palavras e o intérprete — estão inevitavelmente envoltos em historicidade" (JUNKES, 2008, p 128). Logo, fica evidente que a alegoria configura-se numa estratégia de linguagem que se desvincula de um sentido totalizador para ligar-se à ordem do fragmento da significação. Nesse processo de construção de sentidos, perde-se a transparência entre nome e coisa, de forma que o sentido da palavra e o sentido da coisa se distanciem. A objetividade, portanto, cede lugar à subjetividade humana que atribui sentido arbitrário às coisas.

Em Hansen, a alegoria é concebida em duas acepções: a alegoria retórica, ou alegoria dos poetas e a alegoria hermenêutica ou alegoria dos teólogos. Como expressão, “a alegoria dos poetas é uma maneira de falar e escrever" e, segundo Singleton apud Hansen 2006, p. 8, "a alegoria expressiva é intencionalmente tecida na estrutura da própria obra de ficção ou ainda, como afirma R. Hollander, ela é criativa". Sintetizando a distinção, a alegoria dos poetas é uma semântica de palavras essencialmente linguística, ao passo que a dos teólogos, ou hermenêutica é uma semântica de realidades, um modo de decifrar ou uma forma de interpretação religiosa, revelada por coisas, homens e acontecimentos bíblicos (HANSEN, 2006).

Considerando essas distinções, o autor aponta as opções do leitor diante de um texto alegórico: 
Analisar os procedimentos formais que produzem a significação figurada, lendo-a apenas como convenção lingüística que ornamenta um discurso próprio, ou analisar a significação figurada nela pesquisando seu sentido primeiro, tido como preexistente nas coisas, nos homens e nos acontecimentos e, assim, revelado na alegoria (HANSEN, 2006, p. 9).

Em consonância com a proposta de abordagem deste texto, nossa trajetória seguirá pelo viés da alegoria como expressão ou alegoria retórica ou alegoria dos poetas, bem como os princípios assinalados por Benjamin sobre a alegoria como processo de construção de sentidos. Nessa perspectiva, tais conceitos nos auxiliam a compreender a criação literária que constitui o universo ficcional em $O$ outro pé da sereia, obra na qual se particulariza a relação de Mia Couto com a História da colonização de seu país. Explicando sobre a fonte inspiradora dessa obra, o autor afirma:

Um dos núcleos inspiradores foi a leitura de um documento histórico
que relata o encontro do missionário D. Gonçalo da Silveira e o
Imperador do Monomotapa. O encontro é muito sugestivo, rico em
mal-entendidos que revelam códigos culturais diversos. Essa distância
continua a marcar ainda hoje aquilo que se celebra como "encontro de
culturas.

Dessa forma, a narrativa coutiana configura-se numa forma privilegiada de ler a mentalidade de uma época transcrita pela versão oficial, porém longe da intenção de produzir outra verdade histórica. Ao partir de fatos que constam nos registros oficiais, os escritos de Mia Couto fornecem elementos para compreender que a ficção atua com uma maneira própria de tematizar sobre o que a História toma como verdade, preenchendo suas lacunas com uma linguagem poética. Um dos recursos para tal preenchimento se dá por meio da alegoria, concebida por Benjamin (1984) como processo de constituição de sentido. Nessa perspectiva, a força estética das obras é definida pela capacidade da linguagem configurar experiências, podendo apoderar-se de qualquer realidade. Ao fazer incursões na História para recriá-la, o componente alegórico se destaca entre os procedimentos formais adotados pelo escritor para conferir a narrativa um tom de humor e ironia.

Em $O$ outro pé da sereia os tempos movimentam-se numa alternância entre passado e presente. Seguindo esse esquema de interposição, a organização feita pela oscilação de diferentes momentos históricos que fazem referência ao processo de

\footnotetext{
${ }^{3}$ Disponível em: <http://www.portaldaliteratura.com/entrevistas.ph> Entrevista dada em 26/09/2006. Acesso em: 25 jul.2012.
} 
colonização da África pelos portugueses, registra um tempo localizado no passado, no século XVI, de janeiro de 1560 a março de 1561, e um tempo presente, localizado no século XXI, situado em dezembro de 2002.

Assim, a temporalidade que faz referência ao passado é marcada pela evocação da História sobre a travessia do Índico e a incursão dos missionários na África em 1560, com interesse nas riquezas do reino de Monomotapa e a conversão do imperador à fé cristã, conforme descreve o seguinte fragmento:

\begin{abstract}
A nau Nossa Senhora da Ajuda acaba de sair do porto de Goa, rumo a Moçambique. Cinco semanas depois, em Fevereiro de 1560, chegará à costa africana.

[...] Mais do que todos, porém, a nau conduz D. Gonçalo da Silveira, o provincial dos jesuítas na Índia portuguesa. Homem santo, dizem. [...] O propósito da viagem é realizar a primeira incursão católica na corte do Império do Monomotapa. Gonçalo da Silveira prometeu a Lisboa que baptizaria esse imperador negro [...] Por fim, África inteira emergiria das trevas e os africanos caminhariam iluminados pela luz cristã (COUTO, 2006, p. 51).
\end{abstract}

No processo de criação literária de Mia Couto há uma proposta de diluição das fronteiras entre História e ficção. Elementos que fizeram parte da História oficial, também atuam na composição dos cenários ficcionais. Além dos fatos que descrevem a incursão dos portugueses na África, a narrativa de ficção também é composta pela presença do jesuíta D. Gonçalo da Silveira, personagem extraído da História, para atuar na ficção com o intuito de representar o cristianismo como marca da colonização portuguesa. Sua atuação configura-se numa alegoria da missão catequizadora dos portugueses em terras africanas.

As primeiras encenações da narrativa histórica ocorrem no espaço da Nau Portuguesa de Nossa Senhora da Ajuda, quando em 1560 sai do porto de Goa, rumo a Moçambique. Nela viajam marinheiros, funcionários do reino, deportados e escravos que tiveram suas vidas marcadas pelo processo de colonização. Estes enunciam vozes que contestam a imposição da língua e reivindicam a existência da sua, denunciam o apagamento da sua cultura e a imposição da religião dos portugueses sobre suas tradições religiosas. Nesse momento histórico da narrativa, o espaço da nau portuguesa é uma representação alegórica da sociedade colonial. Trata-se de um espaço constituído por representantes das instituições do sistema colonial, designados para exercerem suas funções no processo de colonização em suas representações de poder, dominação e opressão. 
Nos diferentes espaços da nau, encontram-se as representações que constituirão o mosaico cultural que formará a sociedade moçambicana. É nesse navio onde tudo iniciou. Ele é o espaço onde se protagonizam as tensões geradas pelo contato entre as diferentes representações culturais do colonizador e do colonizado.

O hibridismo cultural resultante desse processo é alegorizado pela imagem da santa, representação mística que promove a confluência entre diferentes apropriações. Primeiramente, ela é Nossa Senhora, santa católica para os portugueses, trazida no navio pelos padres jesuítas que tinham a missão de converter os africanos à fé cristã e a imagem era símbolo dessa missão: "A estátua de Nossa Senhora, benzida pelo papa, é o símbolo maior desta peregrinação" (COUTO, 2006, p. 51). Contudo, ainda no navio, a imagem é concebida pelos escravos como Kianda, representação das divindades das águas, conforme expressa a voz do escravo Nimi Nsundi:

- Essa Senhora, eu já conheço, na minha terra chamam de Kianda (COUTO, p. 52).

Dessa forma, a imagem da santa assume a representação da religiosidade dos portugueses, sendo reconhecida como Nossa Senhora, porém sob a ótica dos escravos africanos, a imagem é a representação da deusa Kianda, símbolo das crenças africanas, rainha das águas, que assume as formas de uma sereia, mas que foi transfigurada pelos portugueses ao ter a imagem talhada com dois pés.

Esse deslocamento de sentido se intensifica quando, durante a viagem, o escravo Nsundi serra um dos pés da imagem no intento de libertar sua deusa das águas que estava aprisionada na imagem trazida pelos portugueses. Mais adiante, nas terras do Zimbabwe, a imagem mutilada da santa assume a representação de Nzuzu, deusa que habita as profundezas do rio. Depois, atravessando os tempos, na narrativa desenvolvida no presente, em 2002, a imagem é concebida como Mama Wati, sereia que viajara com os escravos.

Ao promover essas ressignificações, a imagem é uma alegoria da hibridização de culturas que perpassa todo o romance. Como representação híbrida, possibilita a confluência de significados por meio de diferentes signos culturais, não se prendendo, assim, a um sentido único e fixo.

Logo, torna-se visível que os elementos da narrativa são conduzidos a uma busca constante pela restauração da cultura tradicional que conseguiu sobreviver entre trocas e diálogos culturais. Por meio da língua, das crenças e da religiosidade, tal cultura adquiriu diferentes significados, revelando uma existência híbrida que se enriquece e se 
transforma como o outro pé da sereia que é uma alegoria dessas movências no confronto gerado entre portugueses e africanos.

\section{REFERÊNCIAS}

BENJAMIN, Walter. O narrador. In: Magia e técnica, arte e política: ensaios sobre literatura e história da cultura. 7. Ed. Tradução de Sergio Paulo Rouanet. Rio de Janeiro: Brasiliense, 1994.

BENJAMIN, Walter. Origem do Drama Barroco Alemão, Brasiliense, São Paulo, 1984.

BOSI, Alfredo. O ser e o tempo da poesia. São Paulo: Companhia das Letras, 2008.

CHAVES, Rita. Angola e Moçambique: experiência colonial e territórios literários. São Paulo: Ateliê Editorial, 2005.

COUTO, Mia. E se Obama fosse africano? E outras Interinvenções. Lisboa: Editorial Caminho, 2009.

COUTO, Mia. O outro pé da sereia. São Paulo: Companhia das Letras, 2006.

FONSECA, Maria Nazareth Soares; CURY, Maria Zilda Ferreira. Mia Couto: espaços ficcionais. Belo Horizonte: Autêntica Editora, 2008.

FONSECA, Maria Nazareth Soares. Literaturas africanas de língua portuguesa: percursos da memória e outros trânsitos. Belo Horizonte: Veredas e Cenários, 2008.

HANSEN, João Adolfo. O imortal e a verossimilhança. In: Teresa, revista de Literatura Brasileira, SP: Editora 34, Imprensa Oficial, p. 56-78. Vol. 6, 2006.

JUNKES, Lauro. O processo de alegorização em Walter Benajmin. In: Anuário de Literatura. Santa Catarina. 2, p.125-137, 1994.

LEITE, Ana Mafalda. A narrativa como invenção da personagem. In: Navegações. Porto Alegre: EDIPCRS, 2 (1-2), p. 7-11, jun. 2009.

MATA, Inocência. A Alquimia da Língua Portuguesa nos Portos da Expansão em Moçambique, com Mia Couto. In: Scripta. Revista do Programa de Pós-Graduação em Letras e do CESPUC, Belo Horizonte. 1 (1-2), p. 262-268, 1998.

SANTOS, Boaventura de Souza. A gramática do tempo: para uma nova cultura política. 3. Ed. São Paulo: Cortez, 2010.

. Renovar a teoria crítica e reinventar a emancipação social. Trad.

Mouzar Benedito. São Paulo: Boitempo, 2007.

SILVA, Ana Cláudia da. O rio e a casa: imagens do tempo na ficção de Mia Couto. São Paulo: Cultura Acadêmica, 2010. 